\title{
Universal Thermal Climate Index (UTCI) and adverse pregnancy outcomes in Ahvaz, Iran
}

\author{
Narges Khodadadi ${ }^{1}$, Maryam Dastoorpoor ${ }^{1}$, Narges Khanjani ${ }^{2}$ and Afsaneh Ghasemi ${ }^{3^{*}}$
}

\begin{abstract}
Background: Climate change may jeopardize the health of mothers and their offspring. There are few studies on the association between increasing temperature and pregnancy outcomes. The aim of this study was to investigate the relation between Universal Thermal Climate Index (UTCI) and adverse pregnancy outcomes including stillbirth, low birth weight (LBW), preterm labor (PTL), spontaneous abortion (SA), preeclampsia and hypertension in Ahvaz, Iran.

Methods: Distributed Lag Non-linear Models (DLNM) combined with quasi-Poisson regression were used to research the effect of UTCl on adverse pregnancy outcomes. The effect of time trend, air pollutants $\left(\mathrm{NO}_{2}, \mathrm{SO}_{2}\right.$ and $\mathrm{PM}$ 10), and weekdays were adjusted.
\end{abstract}

Results: The results showed that the low values of UTCI index $\left(11.6^{\circ} \mathrm{C}\right.$, in lags $\left.0-6,0-13\right)$ caused significant increase in the risk of preterm labor. However, hot thermal stress (high UTCI) significantly increased the risk of stillbirth in lag 0-13. We did not observe any significant relation between UTCI and other pregnancy outcomes in this study.

Conclusions: It seems like both hot and cold weathers can be associated with adverse pregnancy outcomes.

\section{Plain Language Summary}

Scientists have found that climate change has adverse effects on human health. Because pregnant women are one of the most vulnerable groups, these negative impacts may affect their fetuses, which make up the next generation. In this study, we examined the effect of temperature on some pregnancy outcomes, including low birth weight, preterm labor, spontaneous abortion, preeclampsia and gestational hypertension in Ahvaz city, which is one of the hottest cities in the world.

One way to assess temperature impact on humans is by using temperature indicators. In this study we used the Universal Thermal Climate Index (UTCI) for this purpose. The data at different time intervals were collected and evaluated with specific models.

Our results showed that low values of UTCI, which is equivalent to cold weather, significantly increase the risk of preterm labor. But, high levels of UTCl, which means hot weather, significantly increase the risk of stillbirth.

In conclusion; both hot and cold weather can be associated with adverse pregnancy outcomes in Ahvaz city. Therefore, pregnant women should protect themselves from exposure to hot and cold weather.

Keywords: Temperature, Thermal index, Universal Thermal Climate Index, Pregnancy outcome

*Correspondence: naz7899@yahoo.com

${ }^{3}$ Department of Public Health, School of Public Health, Fasa University of Medical Sciences, Fasa, Iran

Full list of author information is available at the end of the article

\section{Background}

Scientists believe that the adverse health outcomes related to climate change are increasing rapidly [1]. Pregnant mothers and growing embryos are among original author(s) and the source, provide a link to the Creative Commons licence, and indicate if changes were made. The images or other third party material in this article are included in the article's Creative Commons licence, unless indicated otherwise in a credit line to the material. If material is not included in the article's Creative Commons licence and your intended use is not permitted by statutory regulation or exceeds the permitted use, you will need to obtain permission directly from the copyright holder. To view a copy of this licence, visit http://creativecommons.org/licenses/by/4.0/. The Creative Commons Public Domain Dedication waiver (http://creativeco mmons.org/publicdomain/zero/1.0/) applies to the data made available in this article, unless otherwise stated in a credit line to the data. 
the populations most vulnerable to the effects of climate change [2]. However, the effect of increasing temperature on reproductive outcomes is not thoroughly understood [2, 3]. Some studies have reported a possible relation between preterm birth, stillbirth, and low birth weight with ambient temperature [4]. For example, $\mathrm{Yu}$ et al. reported the effect of extreme weather on preterm birth in the tropical island of Puerto Rico [5]. Apparently, increase in temperature in the warm season is significantly more dangerous than the cold season [6], and studies have reported a positive relation between preterm birth and heat wave exposure during pregnancy [7, 8].

There are also several studies which have showed connections between stillbirth and high temperatures during the week before delivery [9-12] or during early pregnancy [7]. In Sweden, Hartig et al. found that the risk of LBW $<1500 \mathrm{~g}$ for male infants increases in the summers with cold weather, which is probably due to the stress caused by the unpleasant weather [13]. Exposure to extreme temperatures in different months of pregnancy may have different results. In a 2017 analysis in the US the risk of low birth weight increased for cold exposures during the second and third trimesters, and for hot exposures during the third trimester of pregnancy [10]. Another study found that women with their first pregnancy in the summer [14] or those exposed to high temperatures during the first trimester of pregnancy, as well as 30 days after pregnancy, had a higher risk for preeclampsia [15]. The relation between gestational hypertension as one of the adverse consequences of pregnancy and temperature in both cold and hot periods has been investigated in several studies, and the incidence was mostly higher in winter [16-19]. Interest in evaluating environmental factors as a determinant of adverse birth outcomes has increased, and one method of investigating this issue is through temperature indices [20].

Since 1950, human thermal comfort in both indoor and outdoor environments has been evaluated in multiple research, leading to various numerical and diagrambased indices [21]. One of the most popular indices used to measure thermal stress in outdoor spaces is the Universal Thermal Climate Index (UTCI) which was proposed more than 10 years ago by the International Society for Biomarkers (ISB) [21]. It is used in key applications such as daily forecasting and alerting, urban and regional planning, environmental epidemiology, and climate impact research across all climates. The purpose of UTCI is to evaluate outdoor thermal conditions, in the main fields of human biometrics, in terms of a onedimensional quantification that summarizes the interaction of ambient temperature, wind speed, humidity, and long and short-wave heat fluxes [22]. UTCI is defined as the equivalent ambient temperature $\left({ }^{\circ} \mathrm{C}\right)$ of a reference environment that provides the physiological response of a reference person, in the real environment [23]. The multi-node model of human thermoregulation is used to calculate the physiological response to meteorological inputs [24].

As global warming continues, the incidence of significant temperature changes are more likely. The aim of the this paper was to study the relation between UTCI and stillbirth, low birth weight (LBW), preterm labor (PTL), spontaneous abortion (SA), preeclampsia and gestational hypertension in Ahvaz, Iran.

\section{Methods \\ Study site}

Ahvaz is the seventh most populous city of Iran and the capital city of Khuzestan province in the southwest of Iran. Ahvaz is located at $31^{\circ} 20^{\prime} \mathrm{N}$ and $48^{\circ} 40^{\prime}$ E. It's area is $185 \mathrm{~km}^{2}$ and it is $12 \mathrm{~m}$ above sea level. In the 2016 census, the population of this city was approximately 1,300,000 (Iran Statistics center, 2016). Ahvaz has a desert climate with hot long summers and short mild winters. Ahvaz is often the hottest city in the world during summer, with high consistent temperature between 45 and $50{ }^{\circ} \mathrm{C}$. The annual average temperature in this city is $25.4{ }^{\circ} \mathrm{C}$. Ahvaz recorded the temperature of $54{ }^{\circ} \mathrm{C}$ which was the highest temperature in the world on June 29,2017 [25].

\section{Data \\ Study population}

Data about adverse pregnancy outcomes including stillbirth, LBW, PTL, SA, preeclampsia and hypertension (diagnosed in the clinic and recorded with date in the patients' files) were collected from the population of pregnant women that visited two big referral hospitals in Ahvaz(the Imam Khomeini, and Razi Hospital), from 2008 to 2018 (10 years). The diagnoses were based on ICD-10 and included the following codes; stillbirth (Z37.1), low birth weight (P07.0), preterm labor (O60), spontaneous abortion (O03), pre-eclampsia (O14), and gestational hypertension (O13).

The data was inquired on a daily basis, from the beginning of April 2008 until March 2018. The total number of pregnant women who visited the Obstetrics and Gynecology department during this 10 -year period was 150,766 .

\section{Meteorological data}

Meteorological parameters including average daily temperature, maximum daily temperature, minimum daily temperature, average wind speed, relative humidity, and cloudiness, from March 20, 2008 to March 20, 2018 were obtained from the Khuzestan Meteorological 
Department. Ahvaz city has one synoptic meteorology station, in which different atmospheric factors such as temperature, type of clouds, rainfall and cloudiness is determined, and recorded at certain hours, daily. This station is $22.5 \mathrm{~m}$ above sea level, at $48^{\circ} 40^{\prime} \mathrm{E}$ longitude and $31^{\circ} 20^{\prime} \mathrm{N}$ latitude, inside Ahvaz.

Data about ambient air pollutants were inquired from the Ahvaz Environmental Protection Organization and included $\mathrm{SO}_{2}, \mathrm{PM}_{10}, \mathrm{NO}_{2}$. There are four air pollution monitoring stations in Ahvaz city and in this study the average of the four stations were used.

\section{Missing data estimation}

Missing air pollutant data were estimated using the EM (Expectation-Maximization) method [26]. The Expectation Maximum method uses the available data to create regression models that estimate missing data. In this method, regression parameters are re-estimated several times and updated regularly using new sets. That is, initially the available data is used to estimate the parameters of the model. Then the available data and the estimated data, are used to re-estimate the missing data. This process is repeated until the difference between two consecutive regression coefficients becomes less than $10^{-6}$ [26]. In this study, there was no missing meteorological data, but there was less than $10 \%$ missing in air pollution data, that was estimated using EM.

\section{UTCI Index}

The UTCI index is calculated based on albedo of skin (\%), albedo of ground (\%), vapour pressure $(\mathrm{hPa})$, relative humidity (\%), dew point temperature $\left({ }^{\circ} \mathrm{C}\right)$, sun altitude (degree), clothing insulation (clo), diffuse solar radiation $\left(\mathrm{W} / \mathrm{m}^{2}\right)$, direct solar radiation on horizontal plane $(\mathrm{W} /$ $\mathrm{m}^{2}$ ), global solar radiation on horizontal plane $\left(\mathrm{W} / \mathrm{m}^{2}\right)$, reflected solar radiation $\left(\mathrm{W} / \mathrm{m}^{2}\right)$, metabolic heat production $\left(\mathrm{W} / \mathrm{m}^{2}\right)$, mean radiant temperature $\left({ }^{\circ} \mathrm{C}\right)$, cloudiness (octants), atmospheric pressure $(\mathrm{hPa})$, gender, air temperature $\left({ }^{\circ} \mathrm{C}\right)$, ground temperature $\left({ }^{\circ} \mathrm{C}\right)$, skin temperature $\left({ }^{\circ} \mathrm{C}\right)$, wind speed $(\mathrm{m} / \mathrm{s})$ and human movement $(\mathrm{m} / \mathrm{s})$. In the lack of access to some of these data, they can be estimated from other data [27]. In order to calculate the UTCI index, some parameters were considered the same for all people. Thus, albedo of skin was assumed to be $30 \%$, albedo of ground $17 \%$, metabolic heat production: $135 \mathrm{~W} / \mathrm{m}^{2}$, atmospheric pressure: $1000 \mathrm{hPa}$, gender: female and human movement: $1.1 \mathrm{~m} / \mathrm{s}$ [27].

Analysis of UTCI index was performed using the RayMan software. The RayMan software is a simulation tool used in human-biometeorology. Details about this software can be found elsewhere [28]. The classification of UTCI index in Iran is presented in Table 1. The thermal comfort range for UTCI is from 9 to $26^{\circ} \mathrm{C}$, this means
Table 1 Thermal sensation and different groups of UTCI

\begin{tabular}{lll}
\hline UTCI $\left({ }^{\circ} \mathrm{C}\right)$ in Iran* & Thermal sensation & Physiological stress level \\
\hline$<-40$ & Very cold & Extreme cold stress \\
-27 to -40 & Cold & Very strong cold stress \\
-13 to -27 & Cool & Strong cold stress \\
0 to -13 & Slightly cool & Moderate cold stress \\
0 to 9 & Comfortable & Slight cold stress \\
9 to 26 & Slightly warm & No thermal stress \\
26 to 32 & Warm & Moderate heat stress \\
32 to 38 & Hot & Strong heat stress \\
38 to 46 & Very hot & Very strong heat stress \\
$>46$ & & Extreme heat stress \\
\hline
\end{tabular}

that in this range there is no thermal stress imposed on humans [29].

In order to investigate the effect of UTCI index on study outcomes, two separate analyses were performed. First, the association between low values (comparison of 1,5 and 25th percentiles relative to no thermal stress) and high values (comparison of 90, 95 and 99th percentiles relative to no thermal stress) of UTCI index, with the risk of adverse pregnancy outcomes, in zero cumulative models of $0-2,0-6,0-13$ and $0-21$ days lag was determined. The median of UTCI, defined as the no thermal stress class, was $17.5{ }^{\circ} \mathrm{C}$ and was used as the basis for comparison with other high and low thermal stress values. Zero cumulative models used in this study were models estimating the effect of exposure from day 0 until a particular day. For example, the $0-2$ model, means the effect observed from day $0($ same day, lag $=0)$ until day 2 (lag $=2$ days).

Second, the association between cold thermal stress (comparison of 1th percentile relative to 25 th percentile) and hot thermal stress (comparison of 75th percentile relative to 99th percentile) of UTCI index with risk of adverse pregnancy outcomes, in zero cumulative models, $0-2,0-6,0-13$ and $0-21$ days lag was calculated according to methods used in previous references [30-32].

\section{Statistical analysis}

In order to investigate the effect of UTCI on adverse pregnancy outcomes, Distributed Lag Non-linear Models (DLNM) combined with quasi-Poisson regression models were used. The DLNM model, is based on cross-basis functions, and is used for simultaneous estimation of the nonlinear relation between exposure and outcome in different time lags [33].

In this study, a natural cubic-spline DLNM was used to determine the nonlinear relation of UTCI index and 
also the cumulative lag effects up to a maximum of 21 days, with adverse pregnancy outcomes.

Spline knots were set at equally spaced values on the log scale of lags. The long term, seasonal trend of adverse pregnancy outcomes was moderated by a natural cubic spline function of time with 7 degrees of freedom per years of study (10 years). $\mathrm{PM}_{10}, \mathrm{SO}_{2}$ and $\mathrm{NO}_{2}$ were controlled using the stratified distributed lag model for up to 7 days lag with 3 degrees of freedom [30]. Also, the variable of holidays and weekdays was adjusted as a categorical variable in the final model [30]. Akaike Information Criterion (AIC) models were used to select the most appropriate model and degrees of freedom (knots) for thermal index and lags [33]. Three degrees of freedom were considered as the best model for thermal index and time lags. The risk ratio and 95\% confidence interval were estimated for the associations. The analysis was performed utilizing $\mathrm{R}$ software version 3.5.3 through the dlnm package. P-values $<0.05$ were considered significant.

\section{Results}

Descriptive index of UTCI, stillbirth, LBW, PTL, SA, preeclampsia and gestational hypertension are presented in Table 2. During the 10-year study period, the highest and lowest adverse pregnancy outcomes were respectively preterm labors (5776 cases) and stillbirths (1965 cases). The mean \pm SD of UTCI was $29.0 \pm 10.1$ (Table 2).

Table 2 Descriptive statistics of adverse pregnancy outcomes, air pollutants and UTCl in Ahvaz city, 2008-2018

\begin{tabular}{llclll}
\hline Variable (mean per day) & $\mathbf{N}$ & Mean \pm SD & Median & Min & Max \\
\hline Stillbirth & 1965 & $0.5 \pm 0.8$ & 0 & 0 & 5 \\
$\mathrm{LBW}^{\mathrm{a}}$ & 863 & $0.2 \pm 0.6$ & 0 & 0 & 5 \\
$\mathrm{PTL}^{\mathrm{b}}$ & 5776 & $1.6 \pm 1.9$ & 1 & 0 & 12 \\
$\mathrm{SA}^{\mathrm{c}}$ & 5063 & $1.4 \pm 1.4$ & 1 & 0 & 8 \\
Pre-eclampsia & 4357 & $1.2 \pm 1.2$ & 1 & 0 & 8 \\
$\mathrm{Gestational} \mathrm{hypertension}$ & 4030 & $1.1 \pm 1.2$ & 1 & 0 & 13 \\
$\mathrm{NO}_{2}{ }^{\mathrm{d}}\left(\mu \mathrm{g} / \mathrm{m}^{3}\right)$ & - & $46.4 \pm 43.1$ & 35.6 & 1.5 & 443.8 \\
$\mathrm{SO}_{2}{ }^{\mathrm{e}}\left(\mu \mathrm{g} / \mathrm{m}^{3}\right)$ & - & $48.8 \pm 57.0$ & 35.9 & 0 & 907.4 \\
$\mathrm{PM}_{10}{ }^{\mathrm{f}}\left(\mu \mathrm{g} / \mathrm{m}^{3}\right)$ & - & $216.9 \pm 278.3$ & 149.2 & 1.8 & 4324.2 \\
$\mathrm{UTCl}^{\mathrm{g}}$ & - & $29.0 \pm 10.1$ & 28.6 & 5.8 & 49.8
\end{tabular}

\footnotetext{
${ }^{a}$ Low birth weight

b Preterm labor

'Spontaneous abortion

d Nitrogen dioxide

e Sulfur dioxide

${ }^{f}$ Particulate matter less than 10 microns

${ }^{g}$ Universal thermal climate index
}

UTCI index and adverse pregnancy outcomes

The results of Table 3 shows that the low value of UTCI index at the 1st percentile compared to no thermal stress, in lags $0-6$ and $0-13$ significantly increased the risk of preterm labor.

Also in the intensified thermal stress analysis, cold thermal stress significantly increased the risk of PTL, in the $0-13$ lagtime. Finally, hot thermal stress increased the risk of stillbirth in lag 0-13, significantly (Table 4, Fig. 1).

\section{Discussion}

According to the World Health Organization and the Lancet Countdown, one of the biggest consequences of climate change is its risk to human health $[34,35]$. The effects of climate change on women's health has been mentioned in some references [36, 37]. These adverse effects are more pronounced in high-risk populations such as pregnant women and their developing fetuses [37].

In the present study, the results showed that hot thermal stress in the UTCI index, increased the risk of stillbirth. Similar results have been observed in other studies, such as Kanner et al. [39], who studied 11,2005 deliveries between 2002 and 2010 and assessed the association of stillbirth with acute changes in ambient temperature in a low-risk population in the US. These researchers stated that every $1{ }^{\circ} \mathrm{C}$ raise in ambient temperature in the week before delivery, increased the risk of stillbirth by $7 \%$ [37]. In the warm weather of the Ghanaian tropics, this increase was $12-15 \%$ per $1{ }^{\circ} \mathrm{C}$ increase in wet-bulb globe temperature (WBGT) [38]. Another study in California found that for every $10{ }^{\circ} \mathrm{F}$ increase in apparent temperature in the warm season, the risk of stillbirth increased by $10.4 \%$ after 2-6 days of delay [38], and Rammah et al. who studied 708 women, in the warm seasons of 2008-2013 in Harris County, Texas, reported a much stronger effect, and stated that each $10{ }^{\circ} \mathrm{F}$ increase in apparent temperature in the week before delivery caused a $45 \%$ increase in stillbirth [9]. There are other studies that have reported the effect of increased temperature in 1 week before delivery on stillbirth $[39,40]$ as well. But one study conducted in Brisbane, Australia, during 2005-2009, stated in addition to the last week of pregnancy, heat stress should also be considered in longer periods, because their results showed that mothers' exposure to high ambient temperatures in the last 4 weeks of pregnancy increased the risk of stillbirth compared to mothers who were only exposed in the previous week [20]. Systematic reviews conducted in the US and China confirm the positive association between climate change and stillbirth $[7,41,42]$. But in contrary to these 
Table 3 The cumulative relative risks of adverse pregnancy outcomes in high and low $\mathrm{UTCl}^{\mathrm{a}}$ values relative to $\mathrm{UTCl}=17.5^{\circ} \mathrm{C}$

\begin{tabular}{|c|c|c|c|c|c|c|c|}
\hline Outcomes & $\begin{array}{l}\text { UTC } \\
\text { val } \\
\left({ }^{\circ} \mathrm{C}\right)\end{array}$ & & Lag 0 & Lag 0-2 & Lag 0-6 & Lag 0-13 & Lag 0-21 \\
\hline \multirow[t]{6}{*}{ Stillbirth } & $H^{b}$ & 46.4 & $1.780(0.793-3.997)$ & $1.200(0.521-2.763)$ & $1.725(0.609-4.890)$ & $2.148(0.529-8.719)$ & $1.911(0.283-12.913)$ \\
\hline & & 44.6 & $1.506(0.721-3.145)$ & $1.190(0.559-2.536)$ & $1.542(0.588-4.044)$ & $1.811(0.480-6.838)$ & $1.627(0.263-10.076)$ \\
\hline & & 43.1 & $1.340(0.667-2.693)$ & $1.179(0.577-2.408)$ & $1.414(0.564-3.548)$ & $1.579(0.439-5.676)$ & $1.411(0.242-8.238)$ \\
\hline & $L^{c}$ & 16.2 & $1.008(0.956-1.064)$ & $0.976(0.927-1.028)$ & 0.957 (0.899-1.019) & $0.946(0.871-1.026)$ & $0.949(0.848-1.061)$ \\
\hline & & 14.4 & $1.004(0.882-1.142)$ & $0.940(0.834-1.059)$ & $0.898(0.776-1.039)$ & $0.890(0.731-1.082)$ & $0.874(0.664-1.150)$ \\
\hline & & 11.6 & $0.949(0.694-1.297)$ & $0.880(0.657-1.178)$ & $0.814(0.562-1.180)$ & $0.858(0.515-1.428)$ & $0.769(0.376-1.573)$ \\
\hline \multirow[t]{6}{*}{ LBW } & $\mathrm{H}$ & 46.4 & $0.623(0.164-2.368)$ & $0.990(0.268-3.658)$ & $2.505(0.488-12.871)$ & $0.781(0.082-7.403)$ & $0.111(0.005-2.342)$ \\
\hline & & 44.6 & $0.647(0.193-2.169)$ & $1.209(0.367-3.984)$ & $2.635(0.577-12.028)$ & $0.959(0.112-8.225)$ & $0.168(0.009-3.175)$ \\
\hline & & 43.1 & $0.665(0.212-2.091)$ & $1.361(0.438-4.231)$ & $2.641(0.618-11.284)$ & $1.056(0.131-8.507)$ & $0.217(0.012-3.850)$ \\
\hline & L & 16.2 & $1.004(0.922-1.093)$ & $0.998(0.921-1.082)$ & $0.96(0.868-1.062)$ & 0.977 (0.852-1.12) & $0.935(0.773-1.132)$ \\
\hline & & 14.4 & $0.954(0.768-1.186)$ & $0.986(0.811-1.201)$ & $0.869(0.679-1.112)$ & $0.833(0.589-1.177)$ & $0.763(0.476-1.223)$ \\
\hline & & 11.6 & $0.763(0.430-1.356)$ & $0.953(0.575-1.578)$ & $0.672(0.349-1.292)$ & $0.475(0.186-1.211)$ & $0.434(0.128-1.474)$ \\
\hline \multirow[t]{6}{*}{ PTL } & $\mathrm{H}$ & 46.4 & $0.988(0.601-1.624)$ & $1.108(0.656-1.872)$ & $1.192(0.617-2.303)$ & $1.012(0.412-2.484)$ & $2.392(0.699-8.193)$ \\
\hline & & 44.6 & $1.058(0.669-1.674)$ & $1.192(0.737-1.926)$ & $1.285(0.697-2.368)$ & $1.078(0.465-2.502)$ & $2.387(0.748-7.616)$ \\
\hline & & 43.1 & $1.103(0.712-1.709)$ & $1.245(0.789-1.965)$ & $1.343(0.749-2.409)$ & $1.115(0.500-2.489)$ & $2.330(0.767-7.079)$ \\
\hline & L & 16.2 & $0.996(0.964-1.029)$ & $0.977(0.947-1.007)$ & $0.985(0.95-1.022)$ & 1.017 (0.97-1.067) & $1.014(0.949-1.082)$ \\
\hline & & 14.4 & $1.009(0.936-1.089)$ & $0.980(0.915-1.049)$ & $1.033(0.950-1.124)$ & $1.101(0.977-1.240)$ & $1.108(0.939-1.307)$ \\
\hline & & 11.6 & $1.087(0.910-1.298)$ & $1.086(0.921-1.282)$ & $1.337(1.074-1.664)$ & $1.449(1.042-2.015)$ & $1.536(0.973-2.425)$ \\
\hline \multirow[t]{6}{*}{ SA } & $\mathrm{H}$ & 46.4 & $1.019(0.584-1.780)$ & $0.997(0.568-1.752)$ & $0.764(0.378-1.543)$ & $0.738(0.285-1.910)$ & $0.723(0.199-2.624)$ \\
\hline & & 44.6 & $0.942(0.570-1.556)$ & $1.026(0.618-1.704)$ & $0.781(0.409-1.494)$ & $0.719(0.292-1.769)$ & $0.708(0.207-2.417)$ \\
\hline & & 43.1 & $0.892(0.556-1.432)$ & $1.043(0.647-1.682)$ & $0.797(0.430-1.479)$ & $0.713(0.299-1.700)$ & $0.707(0.215-2.322)$ \\
\hline & L & 16.2 & $1.006(0.971-1.042)$ & $1.009(0.975-1.043)$ & $1.005(0.964-1.047)$ & 1.009 (0.955-1.066) & $1.036(0.961-1.116)$ \\
\hline & & 14.4 & $0.998(0.919-1.084)$ & $1.013(0.939-1.093)$ & $1.001(0.912-1.098)$ & $1.035(0.913-1.173)$ & $1.094(0.918-1.303)$ \\
\hline & & 11.6 & $0.942(0.776-1.144)$ & $0.999(0.836-1.193)$ & $0.966(0.769-1.213)$ & $1.110(0.811-1.520)$ & $1.201(0.774-1.864)$ \\
\hline \multirow[t]{6}{*}{ Pre-eclampsia } & $\mathrm{H}$ & 46.4 & $0.805(0.458-1.415)$ & $0.770(0.432-1.370)$ & $1.086(0.530-2.225)$ & $1.385(0.529-3.629)$ & $1.166(0.316-4.303)$ \\
\hline & & 44.6 & $0.791(0.475-1.317)$ & $0.772(0.459-1.298)$ & $1.071(0.552-2.075)$ & $1.378(0.555-3.417)$ & $1.126(0.325-3.895)$ \\
\hline & & 43.1 & $0.779(0.481-1.260)$ & $0.774(0.474-1.264)$ & $1.058(0.563-1.987)$ & $1.354(0.566-3.239)$ & $1.073(0.324-3.557)$ \\
\hline & $L$ & 16.2 & $1.028(0.991-1.066)$ & 1.01 (0.976-1.046) & $0.998(0.958-1.04)$ & $1.011(0.958-1.067)$ & $0.998(0.927-1.075)$ \\
\hline & & 14.4 & $1.052(0.966-1.146)$ & $1.033(0.956-1.116)$ & $1.038(0.946-1.139)$ & $1.062(0.935-1.207)$ & $0.982(0.818-1.180)$ \\
\hline & & 11.6 & $1.050(0.857-1.285)$ & $1.091(0.909-1.311)$ & $1.236(0.981-1.557)$ & $1.261(0.900-1.766)$ & $0.936(0.573-1.530)$ \\
\hline \multirow[t]{6}{*}{ Gestational hypertension } & $\mathrm{H}$ & 46.4 & $1.411(0.758-2.626)$ & $1.023(0.549-1.908)$ & $1.351(0.619-2.948)$ & $1.183(0.411-3.409)$ & $1.045(0.249-4.387)$ \\
\hline & & 44.6 & $1.410(0.805-2.470)$ & $1.037(0.589-1.824)$ & $1.455(0.706-2.999)$ & $1.381(0.506-3.767)$ & $1.151(0.292-4.541)$ \\
\hline & & 43.1 & $1.412(0.832-2.396)$ & $1.052(0.617-1.795)$ & $1.544(0.775-3.079)$ & $1.551(0.590-4.080)$ & $1.248(0.330-4.717)$ \\
\hline & $\mathrm{L}$ & 16.2 & $0.968(0.931-1.006)$ & $0.995(0.959-1.031)$ & $0.955(0.913-0.999)$ & $0.962(0.907-1.021)$ & $0.961(0.885-1.043)$ \\
\hline & & 14.4 & $0.932(0.852-1.020)$ & $0.983(0.906-1.067)$ & $0.924(0.834-1.024)$ & $0.963(0.837-1.109)$ & $0.951(0.779-1.160)$ \\
\hline & & 11.6 & $0.897(0.725-1.109)$ & $0.952(0.778-1.165)$ & $0.950(0.731-1.234)$ & $1.110(0.771-1.600)$ & $1.047(0.621-1.764)$ \\
\hline
\end{tabular}

Statistically significant values are given in bold

a Universal Thermal Climate Index $\left({ }^{\circ} \mathrm{C}\right)$

${ }^{\mathrm{b}} \mathrm{High}$ UTCI values

'Low UTCI values

findings, in a cohort study from Sweden, hot weather was not associated with an increased risk of stillbirth, and in fact for every $1{ }^{\circ} \mathrm{C}$ increase in temperature during pregnancy, the risk of stillbirth decreased by $8 \%$ [43]. The reason for these different results, may be due to the differences in climate between Ahvaz (often hot weather) and Sweden (often cold weather), and the fact that people in Sweden face milder heat.

Although the mechanism of the effect of temperature on stillbirth is not yet clear, reduction of amniotic fluid volume, placental damage, or temperature-induced uterine contractions are possible mechanisms $[44,45]$. Heat 
Table 4 The cumulative relative risks of adverse pregnancy outcomes in intensified thermal stress of UTCI

\begin{tabular}{llllll}
\hline & Lag 0 & Lag 0-2 & Lag 0-6 & Lag 0-13 & Lag 0-21 \\
\hline Hot effect (UTCI) & & & & & \\
$\quad$ Stillbirth & $1.591(0.957-2.647)$ & $1.087(0.636-1.858)$ & $1.513(0.825-2.773)$ & $\mathbf{2 . 0 4 9 ( 1 . 0 1 2 - 4 . 1 5 1 )}$ & $2.336(0.853-6.400)$ \\
LBW & $0.892(0.378-2.108)$ & $0.769(0.335-1.766)$ & $1.369(0.538-3.485)$ & $1.074(0.355-3.253)$ & $0.464(0.097-2.218)$ \\
PTL & $0.902(0.672-1.211)$ & $0.897(0.650-1.238)$ & $0.907(0.626-1.313)$ & $0.972(0.613-1.542)$ & $1.376(0.711-2.665)$ \\
SA & $1.231(0.859-1.766)$ & $0.973(0.673-1.409)$ & $0.887(0.586-1.343)$ & $0.932(0.573-1.516)$ & $0.895(0.443-1.809)$ \\
Pre-eclampsia & $1.087(0.759-1.558)$ & $0.965(0.665-1.402)$ & $1.064(0.701-1.615)$ & $1.219(0.742-2.005)$ & $1.524(0.754-3.081)$ \\
Gestational hypertension & $0.979(0.657-1.456)$ & $0.893(0.600-1.331)$ & $0.731(0.466-1.145)$ & $0.585(0.342-1.002)$ & $0.640(0.301-1.360)$ \\
Cold effect (UTCI) & & & & & \\
Stillbirth & $0.973(0.684-1.382)$ & $0.851(0.615-1.176)$ & $0.761(0.509-1.138)$ & $0.778(0.449-1.347)$ & $0.724(0.334-1.567)$ \\
LBW & $0.812(0.437-1.510)$ & $0.965(0.557-1.671)$ & $0.659(0.327-1.325)$ & $0.529(0.195-1.432)$ & $0.448(0.119-1.692)$ \\
PTL & $1.064(0.868-1.303)$ & $1.014(0.845-1.218)$ & $1.229(0.974-1.550)$ & $\mathbf{1 . 4 2 2}(\mathbf{1 . 0 0 8 - 2 . 0 0 6 )}$ & $1.475(0.914-2.380)$ \\
SA & $0.968(0.776-1.207)$ & $1.022(0.836-1.249)$ & $0.983(0.765-1.264)$ & $1.112(0.789-1.568)$ & $1.260(0.778-2.039)$ \\
Pre-eclampsia & $1.118(0.889-1.406)$ & $1.1050(0.900-1.357)$ & $1.187(0.923-1.526)$ & $1.248(0.872-1.788)$ & $0.959(0.569-1.616)$ \\
Gestational hypertension & $0.840(0.660-1.068)$ & $0.943(0.755-1.177)$ & $0.848(0.639-1.124)$ & $0.981(0.663-1.453)$ & $0.932(0.532-1.634)$ \\
\hline
\end{tabular}

Statistically significant values are given in bold

${ }^{\text {a }}$ The cumulative effects of hot thermal stress on adverse pregnancy outcomes, with 99th percentile of UTCI $\left(46.4^{\circ} \mathrm{C}\right)$ relative to 75 th percentile of UTCI $\left(38.0^{\circ} \mathrm{C}\right.$ )

${ }^{\mathrm{b}}$ The cumulative effects of cold thermal stress on adverse pregnancy outcomes, with 1 st percentile of UTCI $\left(11.6^{\circ} \mathrm{C}\right)$ relative to 25 th percentile of UTCI $\left(19.8^{\circ} \mathrm{C}\right)$

stress can cause a decrease of water and blood volume in the mother's body, and this may lead to uterine contractions [46]. Also in heat stress, in order to decrease body heat, blood flow to the periphery increases, and this decreases the perfusion of the placental and umbilical blood [47]. These changes can affect blood pressure and viscosity and ultimately impair the growth and survival of the fetus [48].

Concerning preterm labor, the results of this study indicated that low levels of UTCI and cold thermal stress cause a significant increase in the risk of preterm labor. In support of these results, the results of a study by Bruckner et al. in Uppsala, Sweden, showed that extreme cold increases the risk of preterm labor [43]. Also cohort studies conducted in the US [10] and in Shenzhen, China [49], showed that short-term exposure to cold conditions before delivery increased the risk of preterm birth. However, another study that looked at birth outcomes of 1,020,471 pregnant women from 132 cities in China, reported cold exposure (the 95th percentile) in hot areas reduced the risk of preterm birth; and the protective effect was seen especially in the last 3 months of pregnancy (OR 0.784, 95\% CI 0.734-0.832) [50].

Some studies have stated that both hot and cold weather, affect PTL. For example, a study from Guangzhou, China reported that extreme heat and extreme cold during the last 4 weeks of pregnancy increased the risk of preterm birth by $17.9 \%$ and $10 \%$, respectively [51]. Likewise, in Sabzevar, Iran, both very hot and very cold temperatures were associated with an increase in PTL [52]. $\mathrm{Li}$ et al. [53], in Brisbane, showed that during the years under study (1993-2013), the effect of low temperature was stronger than the effect of high temperature for preterm delivery [53]. However, the results of Basu et al. [12], from California, on approximately 60,000 newborns, showed that high ambient temperature was significantly associated with preterm labor for all mothers, without considering mothers' racial or ethnic group, age, education, or baby gender. The results showed that for every $10^{\circ} \mathrm{F}\left(5.6^{\circ} \mathrm{C}\right)$ increase in weekly mean apparent temperature in lag 6 , the risk of preterm labor increased by $8.6 \%$ (95\% CI 6.0-11.3\%) [12].

The mechanism of the effect of cold air on preterm labor may be related to the effect of cold stress. Experimental research on mammals show that cold weather increases the levels of stress hormones [54, 55] and the transfer of these hormones from mother to fetus may cause earlier birth [56, 57]. Researchers think cold stress increases the level of corticosteroids, and this may accelerate parturition and lead to preterm labor [58]. Increased levels of corticosteroids also suppress the immune system, therefore latent infections are activated and as a result, the risk of preterm labor increases [59].

In terms of other adverse pregnancy outcomes, the results of our study did not show any significant relation between the effect of UTC Index and LBW, SA, preeclampsia and gestational hypertension. In line with our results, the Bruckner study in Sweden (2014) also found no significant relation between ambient temperature and birth weight [43]. But some other articles have observed relations between the effect of ambient temperature (hot weather and cold weather) and these outcomes. For 


\section{$\underline{\text { Hot Effect (UTCI) }}$}

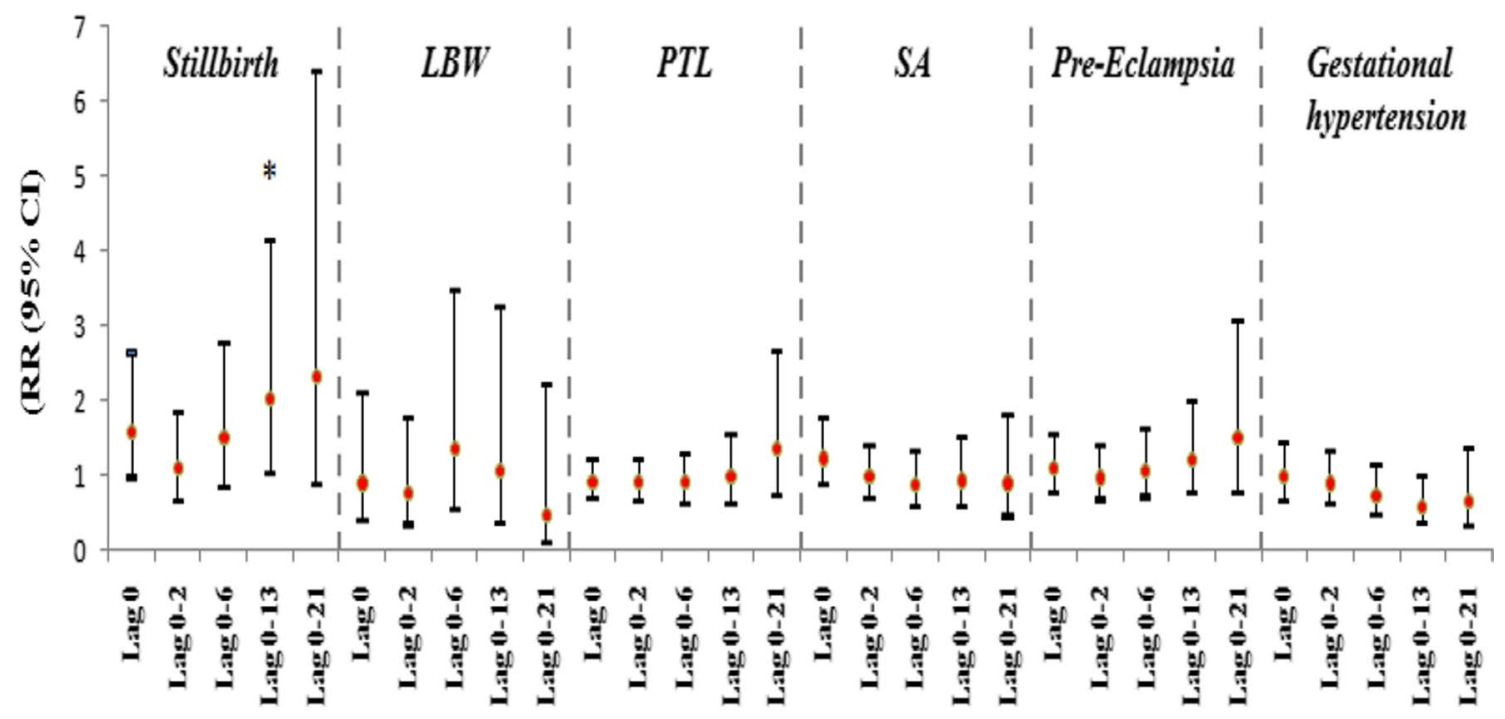

Lag Day

$\underline{\text { Cold Effect (UTCI) }}$

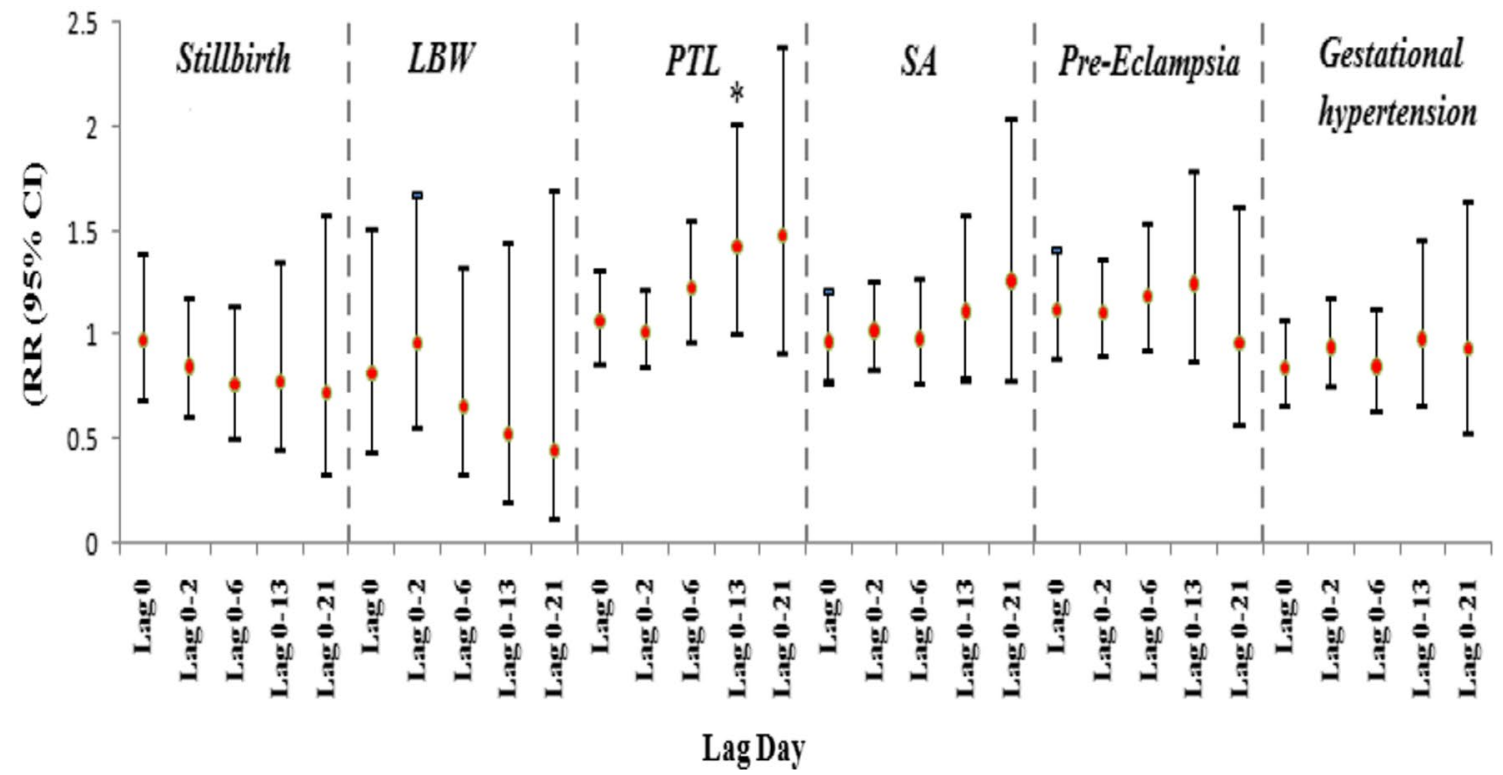

Fig. 1 The relative risks ( $95 \% \mathrm{Cls}$ ) of hot and cold thermal stress of UTCl on adverse pregnancy outcomes at different lag days. *Statistically significant

example, in a recent systematic review including studies conducted in the US, the highest association between climate change and adverse pregnancy outcomes was reported for LBW [41]. Also a large 20-year study in 19 African countries found that the risk of LBW increased significantly, with increased number of hot days [60].
Other studies have reported a positive association between LBW risk and hot weather in the United States $[61,62]$ and cold weather in Sweden [13].

Recently, Sun et al. conducted a case-control study in Guangzhou, China, and found a positive relation between 
exposure to moderate or higher heat during pregnancy and the risk of miscarriage [63].

In the case of gestational hypertension, many studies have observed an increased risk in cold weather [16, 18, 19]. In Brazil, Melo et al. observed that gestational hypertension increased significantly during the colder months, especially in August when the southern hemisphere is in winter [17]. A recent study from China found that exposure to very cold weather before pregnancy increased the risk of preeclampsia, eclampsia and gestational hypertension; and conversely, exposure to cold in the first half of pregnancy reduces, while hot weather increases the risk of hypertensive disorders in pregnancy [64]. But, Elongi et al. found no association between gestational hypertension and seasonal changes, during their 36-month study, in Mississippi [65], which is consistent with the results of the present study. However, Auger et al. conducted a study in Quebec, Canada, and noticed that hot weather during pregnancy increased the risk of preeclampsia, while cold weather increased this risk, only at the end of pregnancy [66]. A study of all deliveries in the Yvelines region of France, between 2008 and 2011 found that high temperature was associated with an increase in severe preeclampsia and the risk was higher when the fetus was conceived in summer than in winter [15]. The reason for the discrepancy between study results may be due to differences in demographic characteristics, adaptation, and seasonal or climate effects $[10,40]$. Also, the different study designs incorporated further complicate the comparison of results [40].

\section{Strengths and limitations}

This was the first study conducted on the relation between the UTCI index and adverse pregnancy outcomes in the world. The results of this study can help in clarifying the effect of climate change on adverse pregnancy outcomes. One of the limitations of this study was that it did not take into account individual characteristics such as living conditions, activity during pregnancy, and clinical reasons which might have been confounders. Meanwhile, we did not have individual data and we could not adjust for these variables. Therefore, the results should be interpreted with caution.

\section{Conclusions}

Overall, our results showed that heat stress measured according to UTCI index was associated with an increased risk of stillbirth, while low levels of UTCI and cold heat stress were associated with increased risk of PTL. But, we did not find a significant relation between the UTCI index with other adverse pregnancy outcomes. The results of this study and similar studies can help promote the general health of pregnant women, raise awareness about the risk of temperature stress, and help reduce the adverse effects of temperature on the next generation.

\section{Abbreviations}

UTCI: Universal Thermal Climate Index; DLNM: Distributed Lag Non-linear Models; $\mathrm{NO}_{2}$ : Nitrogen dioxide; $\mathrm{SO}_{2}$ : Sulfur dioxide; $\mathrm{PM}_{10}$ : Particles with a diameter of less than $10 \mu \mathrm{m}$; EM: Expectation Maximization; AIC: Akaike Information Criteria.

\section{Acknowledgements}

The authors wish to express their gratitude to Ms. Yalda Sabbaghan for her kind assistance.

\section{Authors' contributions}

NK and AG conceived and designed the study, MD analyzed and interpreted the data, NK and NK wrote the paper. All authors read and approved the final manuscript.

\section{Funding}

This study was funded and supported by Ahvaz Jundishapur University of Medical Sciences, Grant No: U-98107.

\section{Availability of data and materials}

Anonymous, group level data is available by communication with the corresponding author.

\section{Declarations}

\section{Ethics approval and consent to participate}

The proposal of this study was approved by the Ethics Committee of Ahvaz Jundishapur University of Medical Sciences (IR.AJUMS.REC.1398.435).

\section{Consent for publication}

Not applicable.

\section{Competing interests}

The authors have no competing interests.

\section{Author details}

${ }^{1}$ Department of Epidemiology and Biostatistics, Menopause Andropause Research Center, Ahvaz Jundishapur University of Medical Sciences, Ahvaz, Iran. ${ }^{2}$ Environmental Health Engineering Research Center, Kerman University of Medical Sciences, Kerman, Iran. ${ }^{3}$ Department of Public Health, School of Public Health, Fasa University of Medical Sciences, Fasa, Iran.

Received: 27 October 2020 Accepted: 3 January 2022

Published online: 02 February 2022

\section{References}

1. Costello A, Abbas M, Allen A, Ball S, Bell S, Bellamy R, Friel S, Groce N, Johnson A, Kett M, Lee M. Managingthe health effects of climate change: lancet and University College London Institute for Global Health Commission.Lancet. 2009;373(9676):1693-733.

2. Rylander C, Øyvind Odland J, Manning Sandanger T. Climate change and the potential effects on maternal and pregnancy outcomes: an assessment of the most vulnerable-the mother, fetus, and newborn child. Glob Health Action. 2013;6:19538.

3. Poursafa P, Keikha M, Kelishadi R. Systematic review on adverse birth outcomes of climate change. J Res Med Sci. 2015;20:397.

4. Strand LB, Barnett AG, Tong S. Maternal exposure to ambient temperature and the risks of preterm birth and stillbirth in Brisbane, Australia. Am J Epidemiol. 2012;175:99-107. 
5. Yu X, Feric Z, Cordero JF, Meeker JD, Alshawabkeh A. Potential influence of temperature and precipitation on preterm birth rate in Puerto Rico. Sci Rep. 2018;8:1-9.

6. Zhong Q, Lu C, Zhang W, Zheng X, Deng Q. Preterm birth and ambient temperature: strong association during night-time and warm seasons. J Therm Biol. 2018;78:381-90.

7. Zhang Y, Yu C, Wang L. Temperature exposure during pregnancy and birth outcomes: an updated systematic review of epidemiological evidence. Environ Pollut. 2017;225:700-12.

8. Carolan-Olah M, Frankowska D. High environmental temperature and preterm birth: a review of the evidence. Midwifery. 2014;30:50-9.

9. Rammah A, Whitworth KW, Han I, Chan W, Hess JW, Symanski E. Temperature, placental abruption and stillbirth. Environ Int. 2019:131:105067.

10. Ha S, Zhu Y, Liu D, Sherman S, Mendola P. Ambient temperature and air quality in relation to small for gestational age and term low birthweight. Environ Res. 2017:155:394-400.

11. Auger N, Fraser WD, Smargiassi A, Bilodeau-Bertrand M, Kosatsky T. Elevated outdoor temperatures and risk of stillbirth. Int J Epidemiol. 2017;46:200-8.

12. Basu R, Sarovar V, Malig BJ. Association between high ambient temperature and risk of stillbirth in California. Am J Epidemiol. 2016;183:894-901.

13. Hartig T, Catalano R. Cold summer weather, constrained restoration, and very low birth weight in Sweden. Health Place. 2013;22:68-74.

14. Tam WH, Sahota DS, Lau TK, Li CY, Fung TY. Seasonal variation in preeclamptic rate and its association with the ambient temperature and humidity in early pregnancy. Gynecol Obstet Invest. 2008;66:22-6.

15. Tran TC, Boumendil A, Bussieres L, Lebreton E, Ropers J, Rozenberg P, Aegerter P. Are meteorological conditions within the first trimester of pregnancy associated with the risk of severe pre-eclampsia? Paediatr Perinat Epidemiol. 2015;29:261-70

16. TePoel MR, Saftlas AF, Wallis AB. Association of seasonality with hypertension in pregnancy: a systematic review. J Reprod Immunol. 2011:89:140-52.

17. Melo B, Amorim M, Katz L, Coutinho I, Figueiroa JN. Hypertension, pregnancy and weather: is seasonality involved? Rev Assoc Med Bras. 2014;60:105-10.

18. Metoki H, Ohkubo T, Watanabe $Y$, Nishimura M, Sato Y, Kawaguchi M, Hara A, Hirose T, Obara T, Asayama K. Seasonal trends of blood pressure during pregnancy in Japan: the babies and their parents'longitudinal observation in Suzuki Memorial Hospital in Intrauterine Period study. J Hypertens. 2008;26:2406-13.

19. Bodnar LM, Daftary A, Markovic N, Schatzman CL, Roberts JM. Seasonal variation in gestational blood pressure. Hypertens Pregnancy. 2006:25:271-83.

20. Strand LB, Barnett AG, Tong S. The influence of season and ambient temperature on birth outcomes: a review of the epidemiological literature. Environ Res. 2011;111:451-62.

21. Abdel-Ghany A, Al-Helal I, Shady M. Human thermal comfort and heat stress in an outdoor urban arid environment: a case study. Adv Meteorol. 2013. https://doi.org/10.1155/2013/693541.

22. Baaghideh M, Mayvaneh F, Shekari Badi A, Shojaee T. Evaluation of human thermal comfort using UTCI index: case study Khorasan Razavi, Iran. Nat Environ Change. 2016;2:165-75.

23. Blazejczyk K, Epstein Y, Jendritzky G, Staiger H, Tinz B. Comparison of UTCI to selected thermal indices. Int J Biometeorol. 2012:56:515-35.

24. Fiala D, Lomas KJ, Stohrer M. Computer prediction of human thermoregulatory and temperature responses to a wide range of environmental conditions. Int J Biometeorol. 2001:45:143-59.

25. Worldatlas: Hottest Cities in the World. Worldatlas.com. https://www. worldatlas.com/articles/the-hottest-cities-in-the-world.html. Accessed 17 Dec 2019

26. Afshari Safavi A, Kazemzadeh Gharechobogh H, Rezaei M. Comparison of EM algorithm and standard imputation methods for missing data: a questionnaire study on diabetic patients. Iran J Epidemiol. 2015;1 1:43-51.

27. Esmailnejad M, Razavi Z. Applied bioclimatic models in environmental planning. Tehran: Mahvareh Publications; 2017.

28. Lee $\mathrm{H}$, Mayer $\mathrm{H}$. Validation of the mean radiant temperature simulated by the RayMan software in urban environments. Int J Biometeorol. 2016;60:1775-85

29. Zare S, Hasheminejad N, Shirvan HE, Hemmatjo R, Sarebanzadeh K, Ahmadi S. Comparing Universal Thermal Climate Index (UTCI) with selected thermal indices/environmental parameters during 12 months of the year. Weather Clim Extremes. 2018;19:49-57.

30. Sharafkhani R, Khanjani N, Bakhtiari B, Jahani Y, Tabrizi JS. Physiological equivalent temperature index and mortality in Tabriz (the northwest of Iran). J Therm Biol. 2018;71:195-201.

31. Yi W, Chan AP. Effects of temperature on mortality in Hong Kong: a time series analysis. Int J Biometeorol. 2015:59:927-36.

32. Luo Y, Zhang Y, Liu T, Rutherford S, Xu Y, Xu X, Wu W, Xiao J, Zeng W, Chu C. Lagged effect of diurnal temperature range on mortality in a subtropical megacity of China. PLoS ONE. 2013;8:e55280.

33. Gasparrini A, Armstrong B, Kenward MG. Distributed lag non-linear models. Stat Med. 2010:29:2224-34.

34. World Health Organization: Climate change and health. 2008.

35. Watts N, Amann M, Arnell N, Ayeb-Karlsson S, Belesova K, Berry H, Bouley T, Boykoff M, Byass P, Cai W. The 2018 report of the Lancet countdown on health and climate change: shaping the health of nations for centuries to come. Lancet. 2018;392:2479-514.

36. Sorensen C, Murray V, Lemery J, Balbus J. Climate change and women's health: impacts and policy directions. PLoS Med. 2018;15:e1002603.

37. Opinion IFoGaOF: Program on reproductive health and the environment: links between prenatal exposure to chemicals and health. University of California San Francisco. 2015. https://prhe.ucsf.edu/international-feder ation-gynecology-and-obstetrics-figo-opinion-reproductive-healthimpacts-exposure. Accessed 4 May 2018

38. Asamoah B, Kjellstrom T, Östergren P-O. Is ambient heat exposure levels associated with miscarriage or stillbirths in hot regions? A cross-sectional study using survey data from the Ghana Maternal Health Survey 2007. Int J Biometeorol. 2018;62:319-30.

39. Kanner J, Williams AD, Nobles C, Ha S, Ouidir M, Sherman S, Mendola P. Ambient temperature and stillbirth: risks associated with chronic extreme temperature and acute temperature change. Environ Res. 2020;189:109958.

40. Ha S, Liu D, Zhu Y, Soo Kim S, Sherman S, Grantz KL, Mendola P. Ambient temperature and stillbirth: a multi-center retrospective cohort study. Environ Health Perspect. 2017:125:067011.

41. Bekkar B, Pacheco S, Basu R, DeNicola N. Association of air pollution and heat exposure with preterm birth, low birth weight, and stillbirth in the US: a systematic review. JAMA Netw Open. 2020;3:e208243.

42. Kuehn L, McCormick S. Heat exposure and maternal health in the face of climate change. Int J Environ Res Public Health. 2017;14:853.

43. Bruckner TA, Modin B, Vågerö D. Cold ambient temperature in utero and birth outcomes in Uppsala, Sweden, 1915-1929. Ann Epidemiol. 2014;24:116-21.

44. Li D-K, Janevic T, Odouli R, Liu L. Hot tub use during pregnancy and the risk of miscarriage. Am J Epidemiol. 2003;158:931-7.

45. He S, Kosatsky T, Smargiassi A, Bilodeau-Bertrand M, Auger N. Heat and pregnancy-related emergencies: risk of placental abruption during hot weather. Environ Int. 2018;111:295-300.

46. Stan CM, Boulvain M, Pfister R, Hirsbrunner-Almagbaly P. Hydration for treatment of preterm labour. Cochrane Database Syst Rev. 2013. https:// doi.org/10.1002/14651858.CD003096.pub2.

47. Ziskin MC, Morrissey J. Thermal thresholds for teratogenicity, reproduction, and development. Int J Hyperth. 2011;27:374-87.

48. Slama R, Darrow L, Parker J, Woodruff TJ, Strickland M, Nieuwenhuijsen M, Glinianaia S, Hoggatt KJ, Kannan S, Hurley F. Meeting report: atmospheric pollution and human reproduction. Environ Health Perspect. 2008:116:791-8.

49. Liang Z, Lin Y, Ma Y, Zhang L, Zhang X, Li L, Zhang S, Cheng Y, Zhou X, Lin $H$. The association between ambient temperature and preterm birth in Shenzhen, China: a distributed lag non-linear time series analysis. Environ Health. 2016;15:84.

50. Guo T, Wang Y, Zhang H, Zhang Y, Zhao J, Wang Y, Xie X, Wang L, Zhang Q, Liu D. The association between ambient temperature and the risk of preterm birth in China. Sci Total Environ. 2018;613:439-46.

51. He J-R, Liu Y, Xia X-Y, Ma W-J, Lin H-L, Kan H-D, Lu J-H, Feng Q, Mo W-J, Wang P. Ambient temperature and the risk of preterm birth in Guangzhou, China (2001-2011). Environ Health Perspect. 2015;124:1100-6.

52. Mohammadi D, Naghshineh E, Sarsangi A, Sakhvidi MJZ. Environmental extreme temperature and daily preterm birth in Sabzevar, Iran: a timeseries analysis. Environ Health Prev Med. 2019;24:5. 
53. Li S, Chen G, Jaakkola JJ, Williams G, Guo Y. Temporal change in the impacts of ambient temperature on preterm birth and stillbirth: Brisbane, 1994-2013. Sci Total Environ. 2018;634:579-85.

54. Morrison SF, Ramamurthy S, Young JB. Reduced rearing temperature augments responses in sympathetic outflow to brown adipose tissue. J Neurosci. 2000;20:9264-71.

55. Canals M, Figueroa D, Miranda J, Sabat P. Effect of gestational and postnatal environmental temperature on metabolic rate in the altricial rodent, Phyllotis darwini. J Therm Biol. 2009;34:310-4.

56. Wadhwa PD, Garite TJ, Porto M, Glynn L, Chicz-DeMet A, Dunkel-Schetter C, Sandman CA. Placental corticotropin-releasing hormone (CRH), spontaneous preterm birth, and fetal growth restriction: a prospective investigation. Am J Obstet Gynecol. 2004;191:1063-9.

57. Sandman CA, Glynn L, Schetter CD, Wadhwa P, Garite T, Chicz-DeMet A, Hobel C. Elevated maternal cortisol early in pregnancy predicts third trimester levels of placental corticotropin releasing hormone (CRH): priming the placental clock. Peptides. 2006;27:1457-63.

58. Hobel C, Culhane J. Role of psychosocial and nutritional stress on poor pregnancy outcome. J Nutr. 2003;133:1709S-1717S.

59. Coussons-Read ME, Okun ML, Nettles CD. Psychosocial stress increases inflammatory markers and alters cytokine production across pregnancy. Brain Behav Immun. 2007;21:343-50.

60. García-Trabanino R, Jarquín E, Wesseling C, Johnson RJ, González-Quiroz M, Weiss I, Glaser J, Vindell JJ, Stockfelt L, Roncal C. Heat stress, dehydration, and kidney function in sugarcane cutters in El Salvador-a crossshift study of workers at risk of Mesoamerican nephropathy. Environ Res. 2015;142:746-55.

61. Sun S, Spangler KR, Weinberger KR, Yanosky JD, Braun JM, Wellenius GA. Ambient temperature and markers of fetal growth: a retrospective observational study of 29 million US singleton births. Environ Health Perspect. 2019;127:067005.

62. Kloog I, Melly SJ, Coull BA, Nordio F, Schwartz JD. Using satellite-based spatiotemporal resolved air temperature exposure to study the association between ambient air temperature and birth outcomes in Massachusetts. Environ Health Perspect. 2015;123:1053-8.

63. Sun X, Luo X, Cao G, Zhao C, Xiao J, Liu X, Dong M, Wang J, Zeng W, Guo L. Associations of ambient temperature exposure during pregnancy with the risk of miscarriage and the modification effects of greenness in Guangdong ,China. Sci Total Environ. 2020;702:134988.

64. Xiong T, Chen P, Mu Y, Li X, Di B, Li J, Qu Y, Tang J, Liang J, Mu D. Association between ambient temperature and hypertensive disorders in pregnancy in China. Nat Commun. 2020;11:1-11.

65. Elongi J-P, Tandu B, Spitz B, Verdonck F. Influence de la variation saisonnière sur la prévalence de la pré-éclampsie à Kinshasa. Gynecol Obstet Fertil. 2011;39:132-5.

66. Auger N, Siemiatycki J, Bilodeau-Bertrand M, Healy-Profitós J, Kosatsky T. Ambient temperature and risk of preeclampsia: biased association? Paediatr Perinat Epidemiol. 2017;31:267-71.

\section{Publisher's Note}

Springer Nature remains neutral with regard to jurisdictional claims in published maps and institutional affiliations.

Ready to submit your research? Choose BMC and benefit from:

- fast, convenient online submission

- thorough peer review by experienced researchers in your field

- rapid publication on acceptance

- support for research data, including large and complex data types

- gold Open Access which fosters wider collaboration and increased citations

- maximum visibility for your research: over 100M website views per year

At BMC, research is always in progress.

Learn more biomedcentral.com/submissions 